\title{
Warrior nurse: duality and complementarity of role in the operational environment
}

\author{
Lauren Griffiths \& Melanie Jasper
}

Accepted for publication 15 August 2007

Correspondence to L. Griffiths:

e-mail: lgriff02@bcuc.ac.uk

Lauren Griffiths BSc MA PhD CertEd ARRC

Portfolio Leader for Practice Learning

Faculty of Health, School of Pre-Registration,

Buckinghamshire Chilterns University

College, Buckinghamshire, UK

Melanie Jasper BNurs MSc PhD RN RHV

RM PGCEA

Head of School of Health Science

Faculty of Health Science, University of

Wales, Swansea, Wales, UK

GRIFFITHS L. \& JASPER M. (2008) Warrior nurse: duality and complementarity of role in the operational environment. Journal of Advanced Nursing 61(1), 92-99 doi: 10.1111/j.1365-2648.2007.04469.x

\section{Abstract}

Title. Warrior nurse: duality and complementarity of role in the operational environment

Aim. This paper is a report of a study to explore the nature of military nursing in an environment of war, in particular the union of personal, professional and organizational tenets and to identify the actual or potential effect this had on the nursing role in this unique environment.

Background. The history of nursing is intrinsically linked with war. There is an irony to this relationship. Active involvement with military activities has provided a vehicle in which nursing has developed, albeit through fostering war, which itself destroys health and contravenes the ethos of nursing. Military nurses, one would assume, are able to reconcile the dichotomy existing between their caring role and being a member of an organization associated with conflict.

Methods. A grounded theory design was adopted and the data were collected from 1999 to 2002 using a series of in-depth interviews and focus group with of 24 military nurses.

Findings. Three categories were identified: 'It's Just Different Levels', 'That Double Hat' and 'It's Who We Are!' The first illustrates the reality of conflict. 'That Double Hat' outlines the military nurses dual role: those of caring and the military. 'It's Who We Are!' demonstrates the transition from nurse-to-warrior. These integrate to create the core category: 'Caring for War: Transition to Warrior'.

Conclusion. The symbiotic relationship of carer and warrior arises as a consequence of strategies used by military nurses to embrace their dual role. Further research is needed to explore the essence of the caring role within a conflict zone from military and civilian perspectives.

Keywords: dual roles, grounded theory, military nursing, nursing roles, operational duty

\section{Introduction}

For those not involved in military activities, the concept of nursing in an organization involved in peacekeeping and war fighting is viewed as contrary to the beliefs and values that underpin health care. Furthermore, war is an antithesis of health on all levels; spiritual, physical, psychological and economical (Crowe \& Hardill 1991). 
However, from the origins of the human race, war has been an integral part of history (Keegan 1997), with a close liaison between medicine and war dating back to antiquity (Lim 1997).

Until the era of Florence Nightingale nursing, on or near a battlefield, was officially confined to men or those in holy orders (Edwards-Rees 1965). The catalyst for the employment of appropriately-trained women to nurse casualties arising from the Crimean war of 1854-1856 was the graphic portrayal of the plight of the soldiers at the battlefront by war correspondents (Hudson \& Stanier 1997). Thus, Florence Nightingale was approached to lead nurses to Scutari to care for the sick and injured (EdwardsRees 1965). As groups of nurses moved into other avenues of care during wartime, their worth became apparent (Taylor 2001). Ultimately, this led in the United Kingdom (UK) to the formation of the Royal Navy, Army and Royal Air Force Nursing Services.

World War I saw the recruitment of many military nurses (Summers 2000) and the portrayal of nursing endeavours in this war greatly assisted the recruitment of nurses in World War II (Summers 2000). However, unlike their predecessors, who were civilian nurses either called to serve or who chose to serve their country during wartime, contemporary military nurses are career nurses (Bassett 1997), and for many the military is their chosen career pathway, either full- or part-time as a member of the Territorial Army. The adoption of rank, uniform, weapons and taking part in general military and annual weapons training, coupled with prior experience of the military environment in peacetime and conflict situations, makes them 'of the military' (Bassett 1997). Henceforth, military nurses belong to two professions, those of caring and the military, and embrace the ethos of both. Inherent within the dual demands of military nursing is the tension between professional responsibilities and military obligations (Hawley 1997). No specific research exploring the duality of the military nursing role came to light during the study.

\section{The study}

\section{Aims}

The aims of this study were to explore the nature of military nursing in an environment of war, in particular the union of personal, professional and organizational tenets and to identify the actual or potential effect this had on the nursing role in this unique environment.

\section{Methodology}

Strauss and Corbin's (1998) model of grounded theory was chosen. This approach aided the discovery of a conceptual framework that goes some way to explain and capture the complex world of the modern military nurse through and from their world view.

\section{Participants}

Participants were recruited from the UK Royal Navy, Army and Royal Air Force. The inclusion criteria required participants to be regular serving members of the military who had worked in a conflict zone within the last 10 years. Participant demographics are detailed in Table 1.

\section{Data collection}

The use of in-depth interviews provided a forum where faceto-face exploration of the participant's world could be undertaken. Interviews were scheduled through negotiation with the participants. Phase 1, open sampling, involved purposive sampling where participants were targeted on the basis of their military/nursing role, their operational experience and therefore what they might contribute to the study. Open sampling started in October 1999 with five military nurses interviewed. Phase 2 involved selective sampling, where 'information rich' participants were approached to enable comparative analysis to take place. This resulted in a further 10 military nurses being interviewed. The interviews lasted between 45 and 90 minutes. Phase 3 involved theoretical sampling to form a focus group of eight military nurses

Table 1 Participant demographics

\begin{tabular}{ll}
\hline Demographics & Range \\
\hline Queen Alexandra's Royal Naval Nursing Service & 2 participants \\
Age (years) & $26-40$ \\
Years of nursing experience & $11-14$ \\
Years of military nursing experience & $11-14$ \\
Operational experience & $1-3$ tours \\
Queen Alexandra's Royal Army Nursing Corps & 16 participants \\
Age (years) & $25-45+$ \\
Years of nursing experience & $4 \cdot 5-25$ \\
Years of military nursing experience & $5-26$ \\
Operational experience & $1-4$ tours \\
Princess Mary's Royal Air Force Nursing Service & 6 \\
Age (years) & $26-40$ \\
Years of nursing experience & $5-15$ \\
Years of military nursing experience & $1-16$ \\
Operational experience & $1-2$ tours \\
\hline
\end{tabular}


and lasted for over 2 hours. All interviews were audio-taped and transcribed verbatim.

\section{Ethical considerations}

This study was approved by the appropriate military and university ethics committees. A research contract was drawn up to provide potential participants with information on the study aim, how the principle of confidentiality would be upheld and how the concept of anonymity would be applied to all study data. More information was given to the participants prior to the interviews and on signing the consent form, which included consent to audio-tape the interview. Participants were reassured that they had the right to withdraw from the study at anytime without prejudice.

\section{Data analysis}

In keeping with the grounded theory approach, constant comparative analysis was used (Strauss \& Corbin 1998). This allowed the analysis of all sources of data simultaneously as well as a cross-interview analysis to shape future interviews (Strauss \& Corbin 1998). Although the process appears as discrete stages in Figure 1, in reality the stages were undertaken simultaneously and in no particular order.

Data analysis was undertaken by hand in three phases: open, axial and selective coding. Open coding started with a surface analysis and the formulation of notes identifying key areas (Wainwright 1994) and occurred on completion of an

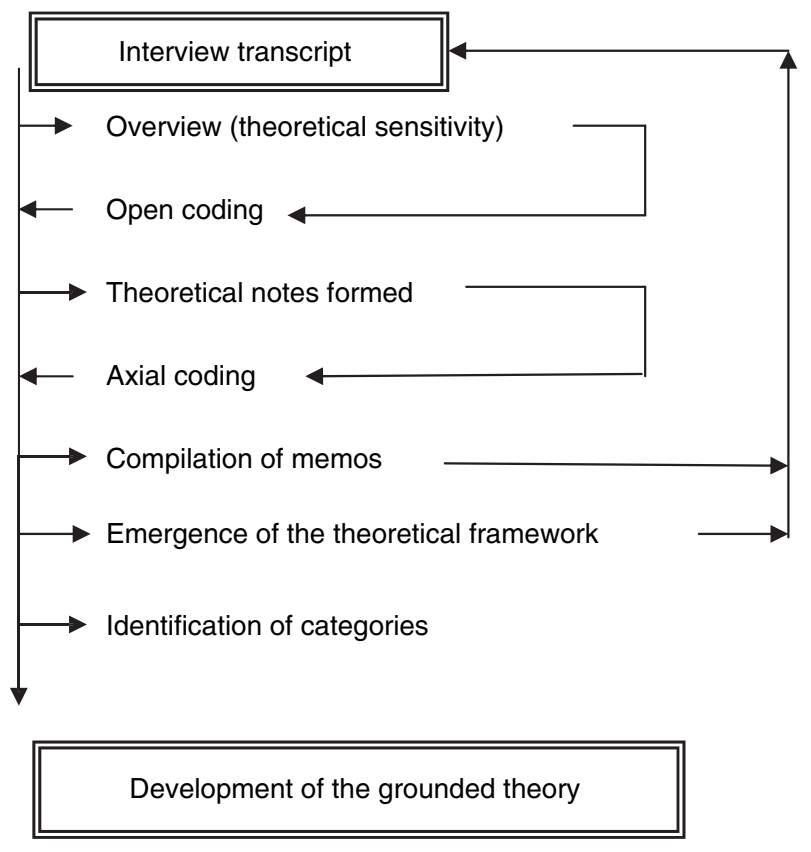

Figure 1 Grounded theory analysis process. interview and prior to the next, with line-by-line examination of the data to identify patterns and themes (Strauss \& Corbin 1998). Descriptive notes relating to the open codes were made (Huberman \& Miles 1994), highlighting how they were defined and allowing the development of open codes (Wainwright 1994).

Axial coding allowed data to be sorted and emerging patterns identified. Data were merged to form categories, which were revised and combined or re-ranked as further data were collected. Examples of axial coding included: 'having a gun' (related with the dual role of nurse and military personnel), 'achieve a balance' (moral stance adopted), 'new ways of working' (role definition) 'spiritual need' (safety blanket), and 'credibility' (badge of office). These were then grouped to formulate sub-categories, 'The Interface of Professions' and 'Value Laden Image' and integrated to illustrate the nature of the category 'That Double Hat'.

The final phase, selective coding, resulted in three categories: 'It's Just Different Levels', 'That Double Hat' and 'It's Who We Are!' These categories came together to form the core category of 'Caring for War: Transition to Warrior', capturing the nature and essence of the study. Saturation was achieved after interviewing 16 military nurses, when no new themes arose. The data were validated and enhanced by a further eight military nurses through the focus group. The overall analysis led to the development of a substantive grounded theory.

\section{Findings}

\section{The grounded theory}

The symbiotic relationship of carer and warrior appears to arise as a consequence of the strategies used by military nurses. These strategies create a psychological comfort zone, allowing the individual to adopt the persona of warrior nurse when needed and thereby allowing them to respond in an appropriate way to the unique challenges of nursing in a conflict zone. Key rites of passage mark the transition from nurse-to-warrior, resulting in what is considered to be a seamless change to act out the core category of 'Caring for War: Transition to Warrior'.

Three categories are presented, using pseudonyms and direct quotations from participants to illustrate their key components.

\section{Category 1: It's Just Different Levels}

'It's Just Different Levels' summarizes the nature of the operational environment from a social and working 
perspective and, in particular, highlights the positive and negative impact this has on the nurses' role. The traditional image typified by two World Wars gives way to peacekeeping and humanitarian aid initiatives at one end of the spectrum and high intensity conflicts, such as the First Gulf War, at the other (McCorquodale 1997).

\section{Sub-category: A Changing World}

For each participant, the experience of war is different. The level of psychological distancing employed by personnel in this situation allows a cocooning society to be established, with defined physical and psychological barriers:

You were almost detached from the whole situation, because we were $100 \mathrm{ks}$ back off the frontline, so apart from the alarms going off for the scud attacks that was about the only thing that really made you think 'Oh, maybe I could be in danger' (Jayne - First Gulf War: Army)

The sense of threat is therefore cushioned by distance and they are able to detach themselves from what is happening as they are removed from the reality of war (McManners 1994). Therefore, those to the rear of the battlefront have different perceptions and experiences of the conflict from those positioned at the front.

The involvement of British forces in complex political conflicts has given rise to a range of diverse operational roles. Role in this context is not ring-fenced or tethered to or constrained by the physical environment:

The time I went operational it was a fairly new concept putting the Aeromed Liaison Officers with field units. So, nobody knew what we were going to do. (Patrick - Bosnia Peacekeeping Mission: RAF)

The developmental aspect of Patrick's role signalled new ways of working and the re-defining of role boundaries, as it was considered to be a 'new concept'. For some, this took them into new roles that required military rather than nursing skills.

Sub-category: The Human Impact of War

Involvement in peacekeeping and humanitarian aid operations potentially exposes members of the military to an environment where moral dilemmas not previously encountered may be prevalent. Respect for humanity and the value of life become lost amid the blatant hatred displayed by hostile parties:

The worse thing was seeing all the ruined houses and kids on the side of the street begging for food. Seeing the way the Serb militia had daubed the walls with some of the atrocities they had committed in the houses. (Tom - Peacekeeping Enforcement Mission Bosnia: RAF)
The human impact on an individual's needs, whereby children are 'begging for food', housing is 'ruined' and safety no longer assured, is evident. Individuals resort to creating an environment of fear and violence, where atrocities are a common event and human trophies are used to heighten and maintain that fear culture (Glover 1999). Fran highlights the problems associated with maintenance of a neutral position:

When you saw what was happening to the Kosovo Albanians and you heard about the rapes, the murders, the slaughtering and the separation of families and just the complete brutality of it all, it was very difficult to try and keep that centre ground. (Fran - Peace Enforcement Mission Macedonia: RAF)

Their moral discomfort is exacerbated further by the confines of the role specification, defined by the overall military operational mission, and their inability to move from that 'centre ground'. The participants' narratives illustrate an altered reality arising from the operational environment, and in particular the human impact of conflict.

\section{Category 2: That Double Hat}

'That Double Hat' illustrates the nature of simultaneously being a member of two professions. Participants acknowledged their duality, in terms of their roles, authority, responsibility and accountability. Challenges inherent with the dual professional status were highlighted, the nature of which is outlined within two sub-categories: 'The Interface of Professions' and 'Value Laden Image'.

\section{Sub-category: The Interface of Professions}

The conflict zone places unique demands on healthcare practitioners in terms of balancing their caring and military roles to ensure that they remain within the codes of practice of those professions:

It's job role at the end of the day. I'm not just answerable to the military, I'm answerable to the civilian side also and at the end of the day the $c^{* *}$ p stops at my door! (Sandra - Peace Enforcement Mission Bosnia: Army)

The obligation to the military is apparent but there is also acute awareness of professional/statutory requirements. The use of 'job role' by Sandra implies that there are specific identifiable skills related to her practice that are well-defined in terms of rights and duties and are clearly expressed in the term 'answerable'.

Unlike their civilian counterparts, military nurses may find themselves having to adopt a 'Jack-of-all-trades' position; general clinical skills are more desirable and serve to assist 
nurses to adapt to clinical demands in a conflict situation. Equally, military nurses can assume a number of sub-roles, sometimes extending far beyond the traditional boundaries of caring:

I was, at the time, the most far north RAF Officer in the Bosnia operation and the only RAF person in the whole Brigade (Army) area.... So I ended up almost running a mini air desk. I was also the local Met(eorology) man. So that double hat was sometimes a quadruple hat: collating the weather, doing the taskings and the aeromed and clinical role as well. (Patrick - Bosnia Peacekeeping Mission: RAF)

In this situation, Patrick has assumed roles which are associated with a general duties RAF officer, organizing a helicopter booking system and collecting and collating the weather forecast for aircrew. His multiple roles demanded competency in a number of roles.

\section{Sub-category: Value Laden Image}

Although there has been a gradual shift towards the militarization of nurses over the last century (Bassett 1997; Taylor 2001), the role expectations associated with nursing remain. The military uniform is a powerful statement of authority that clearly signals the scope and boundaries of the role and the associated skills and behavioural expectation, as does the traditional uniform of nursing. Even when the traditional stereotypic image of a carer is not evident, the caring role remains present and is seen in isolation from the military role and its associated value system:

...the padre is fantastic at welfare. However, you see him as the padre, you don't see him as a Captain, Major or whatever. That is probably why we still have this issue of credibility, where they don't see us as Army people - they see us as people who are going to patch them up when they are injured. (Geraldine - Bosnia Peace Enforcement: Army)

The caring role is aligned to 'welfare' and is seen in the context of someone who will 'patch them up', rather than the warrior role or being 'Army people'. In other words, rank and the associated position in the military is considered to be subordinate to the overriding caring ethic. The issue of credibility, associated with being a member of two professions, is also viewed as problematic in that nurses are not seen as 'Army people'.

\section{Category 3: It's Who We Are!}

'It's Who We Are!' captures the notion that military nurses are comfortable with their dual authority, as well as the challenges to their role and professional position. The high contrast roles of nurse and warrior allow them to cross these boundaries with relative ease, as each is clearly defined in terms of responsibility and authority. The two sub-categories of 'Warrior Nurse' and 'Their Story' illuminate the social and psychological processes used by military nurses in a war zone.

\section{Sub-category: Warrior Nurse}

Under the auspices of North Atlantic Treaty Organisation (NATO), personnel were able to exercise their rights as a soldier, which allowed them to use their weapons for protective purposes. External pressures are fundamental to the transformation from nurse to warrior. Integral to this change is the movement from one role to another, where the individual changes from the expected behaviour of their civilian profession (nursing) to that associated with another social system (Allen \& van de Vliert 1984), in this case the role of warrior:

We set up, with the Gurkhas, a disco for the under 10s in a local village. We were on the way back, we had broken curfew, but had permission to be out late. We were in an open top vehicle and we only had 10 live rounds amongst us. The armoured vehicle with the Gurkhas that was supposed to be protecting us seemed like it was at least a mile behind. Suddenly we came to this civilian roadblock. I leaned over, out of the vehicle, to see what was going on and it was an armed roadblock. At the time I just thought, 'Oh my God! Me or them!' I just went, 'Well make yourself ready'. I basically flipped my safety (catch) off and switched to automatic (fire). I thought, 'I've got 10 rounds, I will spray'. As we were getting ready, the armoured vehicle came and ploughed them (the civilian roadblock) off the road...I never thought I would just flip my safety (catch) off and point my weapon and actually use it. I still don't know if I would, to this day, but I was prepared to at that point. (Sandra - Bosnia Peace Enforcement Mission: Army)

The military ethos becomes dominant and the roles assumed by personnel are based on military rules, regulations and tenets to facilitate the adoption of a 'combatant' stance. In this instance, the transformation from nurse to warrior is triggered by the direct threat, allowing them to cross from one profession to another (Burr 1972) and disengaging from the role of nurse to engage with the role of warrior. The intention to fire is clearly stated, with acknowledgement that to fire the gun would take Sandra away from the philosophical base of 'save a life, not take one'. The highly contrasting roles of nurse and warrior allow a degree of compartmentalization of identities (Ashforth \& Mael 1989, Nippert-Eng 1996). To move from one professional base to another, there is a requirement for the 'mental fences' (Zerubavel 1991) that separate each role to be negotiated and overcome. Participants achieve this by responding to the environmental 
challenge, which in this case is a direct threat to life, by mobilizing the innate instinct to survive.

\section{Sub-category: Their Story}

Military nurses are required to be multi-skilled to respond to the dynamic environment of a conflict zone. To become an integrated and effective member of the military family, a practitioner must be adaptable and flexible and able to reconcile the conflicting identities of nurse and warrior:

I'm comfortable with who I am and what uniform I wear...it allows you to concentrate on what you are actually there to do. What we are interested in is 'Can you do your professional job in the environment of the field?' I think that is a key skill for the military nurse. (Philip First Gulf War: Army)

Military nurses are considered to be 'professional warriors' in that they hold a dual professional position and consider the codes and values of the professions to be in harmony. This allows an individual to 'concentrate' on their operational role. Doing a 'professional job' in the difficult conditions associated with the 'field' is considered to be of great importance. Socialization, training and identification with the professional standing of military nursing are therefore central to reconciliation of the two roles, in that the processes enable the individual to be socialized into the wider military organization.

\section{Core category: Caring for War: Transition to Warrior}

The categories, 'It's Just Different Levels', 'That Double Hat' and 'It's Who We Are' and their associated sub-categories, combine to formulate the core category 'Caring for War: Transition to Warrior', diagrammatically represented in Figure 2. The core category summarizes the processes within the categories to illustrate their world and illuminate the strategies used by military nurses to embrace the transition to warrior. The socially-structured processes and strategies used by military nurses are illustrated by the enactment of the core category.

\section{Study limitations}

The study limitations are primarily associated with the study cohort and the timeframe between the last data collection phase and publication. At the start of the study, few Royal Navy nurses had been involved in front-line operational duties. Latterly, they have played an active role in a broad spectrum of conflicts, including undertaking roles that were

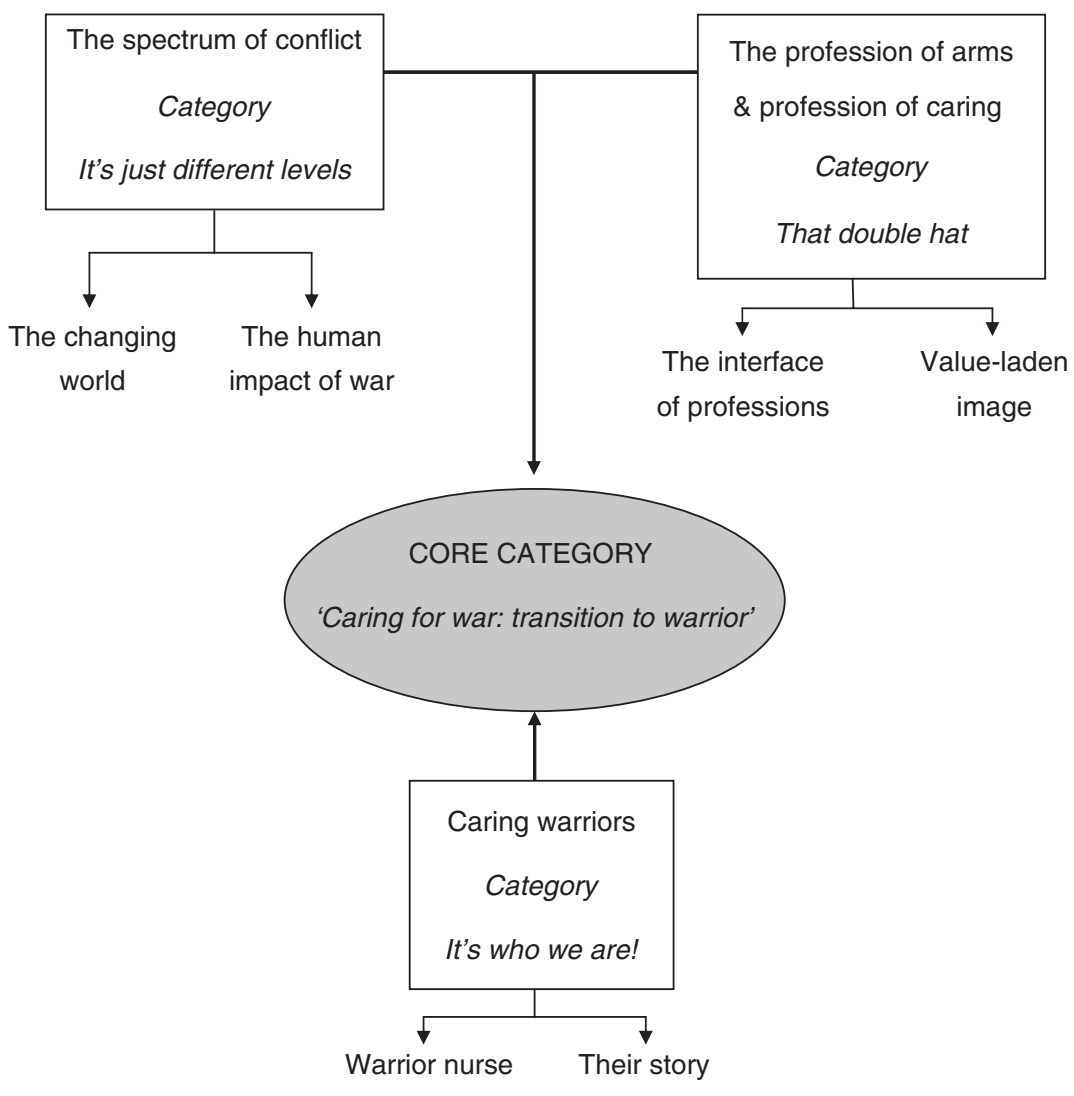

Figure 2 Mapping the concepts. 


\section{What is already known about the topic}

- Research into the nature and essence of military nursing has been largely ignored.

- The literature concentrates on traditional conflicts associated with the first and second world wars and the Vietnam war.

- Descriptive accounts of the role played by military nurses during humanitarian and peacekeeping operations abound.

\section{What this study adds}

- The world of the contemporary military nurse is complex, in particular in relation to the unique challenges of the transition from nurse to warrior.

- The roles of soldier and carer may be in conflict at times.

- Further research is needed to explore the essence of the caring role within a conflict zone from military and civilian perspectives.

traditionally ring-fenced for a particular service, e.g Army nurses. This study is therefore time-bound, a snapshot of their lived experience. It would be reasonable to expect any replication of this study to include a higher number of Royal Navy nurses.

The data collection phase of the study was completed in 2002. However, the findings remain current and continue to be validated through the lived experiences of military nurses serving in Iraq and Afghanistan. Despite the change of location, the nature of modern conflict remains extant, as does the evolving role of the military nurse.

\section{Conclusion}

As the involvement of military nurses in conflicts continues, the importance of adequate preparation for the range of roles they are required to adopt should not be under-estimated. They require adequate and appropriate military and professional training to enable them to function at an optimal level, and flexibility and transferability of skills are central features. A multi-skilled workforce allows the military to respond to the competing and changing demands prevailing within a conflict environment so they can reasonably meet these.

It is vital that military nurses are able to work alongside mainstream military personnel, including United Nations and NATO personnel, Non-governmental Organisations (NGOs) and local civilian organizations, to ensure that optimum care is given to injured military personnel and the local civilian population. The experiences of military nurses will be relevant not only to military nurses, but also to NGOs and other civilian organizations working in conflict zones. Although members of these other organizations do not carry arms, the challenges prevalent within that environment pose similar challenges to their roles. Specific preparation and opportunities for shared learning with all parties, military and civilian, would be beneficial prior to entering that environment.

Further research is required to capture the essence of the caring role within a conflict zone to prepare military, NGO and civilian personnel for their work. Undertaking further research in this unique and under-researched field will contribute to the development of the substantive and/or grand theory: further research should include support and military personnel and make comparisons with NGOs, such as the Red Cross or Mèdicins sans Frontières.

\section{Author contributions}

LG was responsible for the study conception and design and LG and MJ were responsible for the drafting of the manuscript. LG performed the data collection and data analysis. LG made critical revisions to the paper. MJ supervised the study.

\section{References}

Allen V.L. \& van de Vliert E. (1984) A role theoretical perspective on transitional process. In Role Transitions: Explorations and Explanations (Allen V.L. \& van de Vliert E., eds), Plenum, New York, pp. 3-18.

Ashforth B.E. \& Mael F. (1989) Social identity theory and the organization. Academy of Management Review 14, 20-39.

Bassett A. (1997) Guns and Brooches: Australian Army Nursing from the Boer War to the Gulf War. Oxford University Press Australia, Oxford.

Burr W.R. (1972) Role transitions: reformulation of theory. Journal of Marriage and the Family 34, 407-416.

Crowe C. \& Hardill K. (1991) Nursing and war: transforming our legacy. The Canadian Nurse 87, 291-302.

Edwards-Rees D. (1965) The Story of Nursing. Longmans, London. Glover J. (1999) Humanity: A Moral History of the Twentieth Century. Jonathan Cape, London.

Hawley A. (1997) A form of human intercourse. Military Medicine $162,597-600$.

Huberman A.M. \& Miles M.B. (1994) Qualitative Data Analysis. Sage, London.

Hudson M. \& Stanier J. (1997) War and the Media. Sutton Publishing, Stroud.

Keegan J. (1997) War and our World: The Reith Lectures 1998. Pimlico, London. 
Lim M.K. (1997) War and the medical profession. Anals, Academy of Medicine 2, 1-2.

McCorquodale B. (1997) The impact of today's society on tomorrows armed forces. Journal of Defence Science 2, 142-151.

McManners H. (1994) The Scars of War. Harper Collins, London.

Nippert-Eng C.E. (1996) Home and Work: Negotiating Boundaries Through Every Day Life. University of Chicago Press, Chicago, IL. Strauss A. \& Corbin J. (1998) Basics of Qualitative Research. Sage, London.
Summers A. (2000) Angels and Citizens: British Women as Military Nurses 1854-1914. Threshold Press Ltd, Newbury.

Taylor E. (2001) Wartime Nurse: One Hundred Years from the Crimea to Korea 1854-1954. Robert Hale, London.

Wainwright S.P. (1994) Analysing data using grounded theory. Nurse Researcher 1, 43-49.

Zerubavel E. (1991) The Fine Line: Making Distinctions in Everyday Life. Free Press, New York. 